\title{
The burden of cardiovascular disease and cancer attributable to low fruit and vegetable intake in the European Union: differences between old and new Member States
}

\author{
Joceline Pomerleau*, Karen Lock and Martin McKee \\ European Centre on Health of Societies in Transition, London School of Hygiene and Tropical Medicine, \\ Keppel Street, London WCIE 7HT, UK
}

Submitted 21 July 2005: Accepted 21 November 2005

\begin{abstract}
Objective: To estimate the burden of disease attributable to low fruit and vegetable intake in the 15 countries that were members of the European Union (EU) before May 2004 (EU-15) and the 10 countries that then joined it (EU-10).

Design: Data on fruit and vegetable intake, target levels of intake and estimates of relative risks, deaths and disability were combined to obtain the burden of ischaemic heart disease, ischaemic stroke and four types of cancer (lung/bronchus/trachea, stomach, oesophagus, and colon/rectum) attributable to low fruit and vegetable consumption.

Setting: EU-15 and EU-10 Member States.

Results: The number of lives potentially saved annually from the selected outcomes if fruit and vegetable intake increased to $600 \mathrm{~g}_{\text {person }}{ }^{-1}$ day $^{-1}$ reached 892000 and 423000 in the EU-15 and EU-10, respectively; total disease burden could decrease by $1.9 \%$ and $3.6 \%$, respectively. The burden of ischaemic heart disease and stroke could be reduced by up to $17 \%$ and $10 \%$, respectively, in the EU-15 and by $24 \%$ and $15 \%$, respectively, in the EU-10; potential reductions for the selected cancers varied from $1 \%$ to $12 \%$ in the EU-15 and from $2 \%$ to $17 \%$ in the EU- 10.

Conclusions: The potential health gain of increased fruit and vegetable intake is particularly large in the new Member States, and particularly high for cardiovascular diseases, a main cause of health divide in Europe. This stresses the need for better nutrition programmes and policies that take account of economic, social and cultural specificities.
\end{abstract}

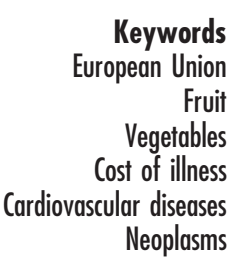

Keywords

Union

getables

illness

Neoplasms
Cardiovascular diseases and cancer represent an enormous public health challenge in the European Union (EU), now and in the foreseeable future ${ }^{1,2}$. They are the main causes of premature death and disability, accounting respectively for over 1.9 and 1.1 million deaths each year ${ }^{3}$. This means that nearly half ( $\left.42 \%\right)$ of all deaths in the EU are from cardiovascular diseases and a quarter from cancer. Looking beyond mortality, the burden of disease attributed to cardiovascular disease and cancer is also extremely high ${ }^{3}$. Cardiovascular disease and cancer are respectively the second and third main causes of disability-adjusted life years (DALYs) lost each year (18\% and 15\%, respectively), just below neuropsychiatric disorders (25\%).

There is now accumulating evidence that fruit and vegetable consumption can play a role in the prevention of these major diseases, thus reducing premature deaths and disability $^{1,4-10}$. Early studies estimated that low fruit and vegetable consumption could be responsible for $2.4 \%$, $2.8 \%$ and $3.5 \%$ of the overall burden of disease in
New Zealand, Australia and the EU (before May 2004), respectively ${ }^{11-13}$. Another study reported that up to 23000 premature deaths (before the age of 65 years) from cardiovascular diseases and major cancers could have been prevented in the EU in the mid-1990s if mean fruit and vegetable consumption had reached the minimum recommended intake level ${ }^{14}$. More recent findings from the World Health Organization (WHO) Global Burden of Disease (GBD) study suggested that increasing individual fruit and vegetable consumption to $600 \mathrm{~g} \mathrm{day}^{-1}$ (equivalent to 7.5 standard portions) could reduce the total burden of disease in Europe by up to $4.4 \%{ }^{15}$. This would represent a major global health gain, but large variations exist within the region. For example, depending on the part of Europe (WHO divides Europe into three sub-regions based on a combination of child (under 5 years) and adult (15-59 years) mortality: 'Very low child and adult mortality', 'Low child and adult mortality' and 'Low child mortality and high adult mortality'), the burden of disease attributable to low fruit and vegetable intake varies between 19 and 35\% for 
ischaemic heart disease, 12 and 23\% for stroke, 13 and $24 \%$ for stomach and oesophageal cancers, 8 and $16 \%$ for lung cancer, and 1 and 3\% for colorectal cancer ${ }^{16}$.

On 1 May 2004, the EU underwent an unprecedented enlargement, from 15 to 25 countries, increasing its population by $20 \%$ to more than 450 million. This enlargement is important not only because of its scale but also because of the gap in health status and lifestyles between the former and new Member States, including major differences in cardiovascular and cancer death rates and in fruit and vegetable intake $\mathrm{e}^{17-19}$. In these circumstances, it is relevant to estimate the burden of cardiovascular disease and cancer attributable to low consumption of fruit and vegetables in the 15 countries that were EU Member States prior to May 2004 (EU-15) and in the 10 countries that became Member States in May 2004 (EU-10).

\section{Methods}

The burden of cardiovascular disease and cancer attributed to low fruit and vegetable intake in the EU was estimated using methods developed for the GBD 2000 project $^{20}$; a summary of these methods is provided below. Estimates were derived separately for the EU-15 and EU-10.

\section{Sources of data}

Four sources of information were combined to obtain burden of disease estimates.

\section{Estimates of fruit and vegetable consumption}

We used an aggregate measure of fruit and vegetable intake, defined as total fruit and vegetable consumption excluding potatoes, to be consistent with current international recommendations ${ }^{1,6}$. Fruit and vegetable intake was treated as a continuous variable and expressed in g person ${ }^{-1}$ day $^{-1}$. Estimates of consumption were based primarily on national representative surveys of individual dietary intake identified through a comprehensive search of the literature and contact with experts. Survey data have the advantage of providing individual-level dietary data on intakes and their variability (standard deviations) in population subgroups (by age and sex strata). Data were obtained for 11 EU countries (Belgium, Denmark, Estonia, Finland, France, Germany, Ireland, Italy, Latvia, Lithuania and the UK) $)^{20,21}$. Systematic extrapolations were made when the original data did not conform to the age/sex categories used. When no survey data were available in a country, estimates of fruit and vegetable intakes were derived from per capita food supply statistics from the Food and Agriculture Organization of the United Nations (FAO) combined with survey information from other EU countries. The FAO collects food balance data each year from virtually all countries in the world using a standardised approach $^{22}$. FAO data ${ }^{23}$ on fruit (excluding wine) and vegetable (excluding potatoes) availability, and population size estimates ${ }^{24}$ for the year 2000, were used in the calculations. However, because food supply figures tend to overestimate intakes in developed countries, the results were adjusted by a correction factor of $33 \%$, derived from published literature ${ }^{14}$. As food balance sheet data do not provide information on intakes consumed within different age/sex categories, an attempt was made to estimate how the total availability of fruit and vegetables in countries with no survey data would be distributed among the different sex and age groups. To reach this objective, a two-step process was used. In the first step, where survey data were available, they were used to obtain an average distribution of total fruit and vegetable intake among different age/sex groups in the EU. In step 2, this average distribution of intakes was used to distribute the total consumption, derived from FAO availability data, within those countries with no survey data. This approach has been described in detail elsewhere ${ }^{21}$.

Standard deviations for the mean intakes were obtained by statistically pooling available survey data; the same estimates were used for the EU-15 and EU-10.

\section{Target level of fruit and vegetable consumption}

Fruit and vegetable intake is unusual in that there is an inverse disease-risk relationship, i.e. it is the potential protective effect of fruits and vegetables that is considered. Hence, the theoretical minimum risk involves selecting a plausible maximum consumption level at which the protective effect is maximised. Two population targets were selected for the analyses. The first target, 400 g person $^{-1}$ day $^{-1}$, corresponds to current recommendations for fruit and vegetable intake and equates to individuals consuming approximately five portions per day $^{1,6}$; it is considered as a minimum goal. The second target was chosen on the basis of the range of intakes and the highest levels of current fruit and vegetable intake in the $\mathrm{EU}^{20}$. This was set at $600 \mathrm{~g}_{\text {person }}{ }^{-1}$ day $^{-1}$ in adults. Given the uncertainty of the evidence, the same thresholds were assumed to apply equally to all selected health outcomes and to all adult populations of both genders.

\section{Relative risks}

Systematic reviews of the literature were conducted for ischaemic heart disease, stroke and cancers of the lung/bronchus/trachea, stomach, oesophagus and colon/rectum using standardised methods ${ }^{20}$. Strict criteria were applied to select only the best-quality and most representative studies that would allow fruit and vegetable intake to be treated as a continuous variable (to correspond to exposure estimates). When two or more studies were available, the results were pooled using meta-analysis following standardised procedures ${ }^{20}$. For oesophageal cancer, the results of a recent meta-analysis were used ${ }^{11}$. Because there is currently little evidence for significant variations in relative risks by age and gender, 
the estimates were applied to both genders and to all age groups between the ages of 15 and 70 years. Approximate age attenuations were then applied as follows: relative risks were reduced by $25 \%$ for individuals aged $70-79$ years and by $50 \%$ for those 80 years and over. Under the age of 15 years a relative risk of 1 was applied. The relative risks thus estimated have been published elsewhere ${ }^{16}$.

\section{Estimates of deaths and disability}

Estimates of deaths and disability for the selected outcomes in the EU-15 and EU-10 were provided by Colin Mathers and Steve Van der Hoorn (see Acknowledgements section).

\section{Statistical analyses}

The statistical analyses involved estimating populationattributable fractions for each outcome. In this project, the attributable fraction was defined as the percentage reduction in disability and death that would occur if fruit and vegetable consumption increased from current levels to the target level associated with the theoretical lowest population risk ${ }^{25,26}$. DALYs were used as a measure of the burden of disease.

\section{Results}

\section{Fruit and vegetable intake and relative risk estimates}

Estimates of mean fruit and vegetable intakes and standard deviations stratified by gender and age are given in Table 1. Intakes were generally lower in the EU-10 compared with EU-15 in both males and females.

Table 1 Estimated pooled mean fruit and vegetable intakes (gperson ${ }^{-1}$ day $^{-1}$ ) in the European Union and pooled standard deviations, by gender and age group

\begin{tabular}{|c|c|c|c|c|c|c|c|c|}
\hline & \multicolumn{8}{|c|}{ Age group (years) } \\
\hline & \multicolumn{8}{|c|}{$930-44 \quad 45-5960-6970-7980+$} \\
\hline Pooled mea & $a n$ & & & & & & & \\
\hline \multicolumn{9}{|c|}{ EU-25 } \\
\hline Males & 235 & 294 & 402 & 451 & 487 & 522 & 521 & 484 \\
\hline Females & 237 & 295 & 406 & 451 & 479 & 490 & 483 & 469 \\
\hline \multicolumn{9}{|c|}{ EU-15 } \\
\hline Males & 245 & 316 & 434 & 468 & 513 & 535 & 528 & 477 \\
\hline Females & 248 & 316 & 438 & 467 & 509 & 513 & 501 & 465 \\
\hline \multicolumn{9}{|c|}{ EU-10 } \\
\hline Males & 177 & 200 & 271 & 358 & 355 & 440 & 474 & 553 \\
\hline Females & 179 & 202 & 274 & 361 & 338 & 368 & 381 & 502 \\
\hline \multicolumn{9}{|c|}{ Pooled standard deviation } \\
\hline Males & 348 & 353 & 396 & 343 & 388 & 312 & 338 & 290 \\
\hline Females & 280 & 277 & 331 & 287 & 294 & 295 & 311 & 267 \\
\hline
\end{tabular}

EU-25 - all current Member States of the European Union (EU); EU-15 the 15 countries that were members before May 2004; EU-10 - the 10 countries that then joined it.

\section{Mortality and disease burden attributable to low fruit and vegetable intake}

The results of the analyses indicate that increasing fruit and vegetable intake in the EU to 400 or 600 g person $^{-1}$ day $^{-1}$ (the two target intake levels) could reduce the total burden of disease by $0.7 \%$ and $1.7 \%$, respectively, in the EU-15 and by $1.9 \%$ and $3.6 \%$, respectively, in the EU-10.

Figures 1 to 3 show the contribution of low fruit and vegetable intake to the burden of ischaemic heart disease, stroke and the selected cancers in the EU-15 and EU-10, stratifying by gender and using both target levels of intake. If the populations of the EU Member States were able to increase their fruit and vegetable intake to the minimum recommended level of $400 \mathrm{~g}_{\text {person }}{ }^{-1}$ day $^{-1}$, this could reduce disability and death from ischaemic heart disease by up to $6 \%$ in the EU-15 and by up to $11 \%$ in the EU-10 (Fig. 1). However, $400 \mathrm{~g}_{\text {person }}{ }^{-1} \mathrm{day}^{-1}$ is the lowest dietary goal. Thus, if people across the EU were to consume the same amounts of fruit and vegetables as in the highest consuming countries such as Greece, Spain or Italy, the burden of ischaemic heart disease could be reduced by up to $17 \%$ in the EU-15 and by almost a quarter (24\%) in the EU-10. The potential health gain would be greatest for ischaemic heart disease, stroke and cancers of the stomach and oesophagus. It would also be greater in males than in females in both the EU-15 and EU-10.

The total number of deaths from the selected six health outcomes that could potentially be prevented annually in the EU-15 and EU-10 is given in Table 2. In the EU-15, the number of deaths that could be saved ranges from about 44000 to 121000 , (for increases to 400 and 600 g person $^{-1}$ day $^{-1}$, respectively). Although the total number of deaths potentially saved annually is lower in the EU-10 (between 20000 and 46000 ), this represented a higher death rate because of the lower population size; this is true for the overall results and for all health outcomes. The impact on mortality is greatest for ischaemic heart disease, followed by ischaemic stroke and lung cancer. In both the EU-15 and EU-10 it is greater among men than women for each disease.

The burden of disease for men and women attributable to low fruit and vegetable intake is presented in Table 3. The results suggest that between 341000 and 892000 DALYs in the EU-15 and between 197000 and 423000 DALYs in the EU-10 could potentially be saved each year if fruit and vegetable intake was increased (to 400 or $600 \mathrm{~g}_{\text {person }}{ }^{-1} \mathrm{day}^{-1}$ ); of these, almost $60 \%$ in the EU-15 and almost two-thirds in the EU-10 come from coronary heart disease. Taking into account population size, the health gain is greater in the EU-10 than in the EU-15 for each health outcome (approximately 1.2- to 2.7-fold benefit), and it is greater in men than in women.

Finally, differences between the EU-15 and EU-10 Member States suggest that people from the new Member States experience ischaemic heart disease, stroke and the selected cancers linked to lack of fruit and vegetables at 


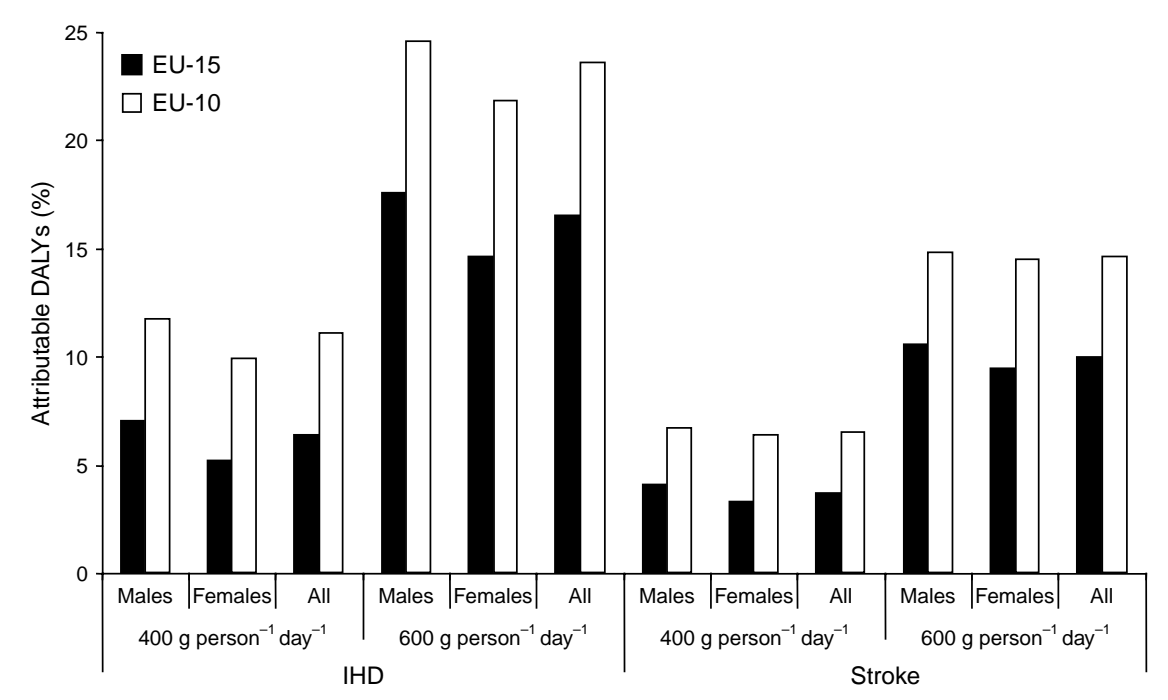

Fig. 1 Potential reduction in the burden of ischaemic heart disease (IHD) and ischaemic stroke (expressed in attributable disabilityadjusted life years, DALYs) due to low fruit and vegetable intake in the EU-15 and EU-10 that could be achieved if fruit and vegetable intake increased to 400 and 600 g person $^{-1}$ day $^{-1}$, by gender (figures for the year 2000). EU-15 - the 15 countries that were members of the European Union (EU) before May 2004; EU-10 - the 10 countries that then joined it

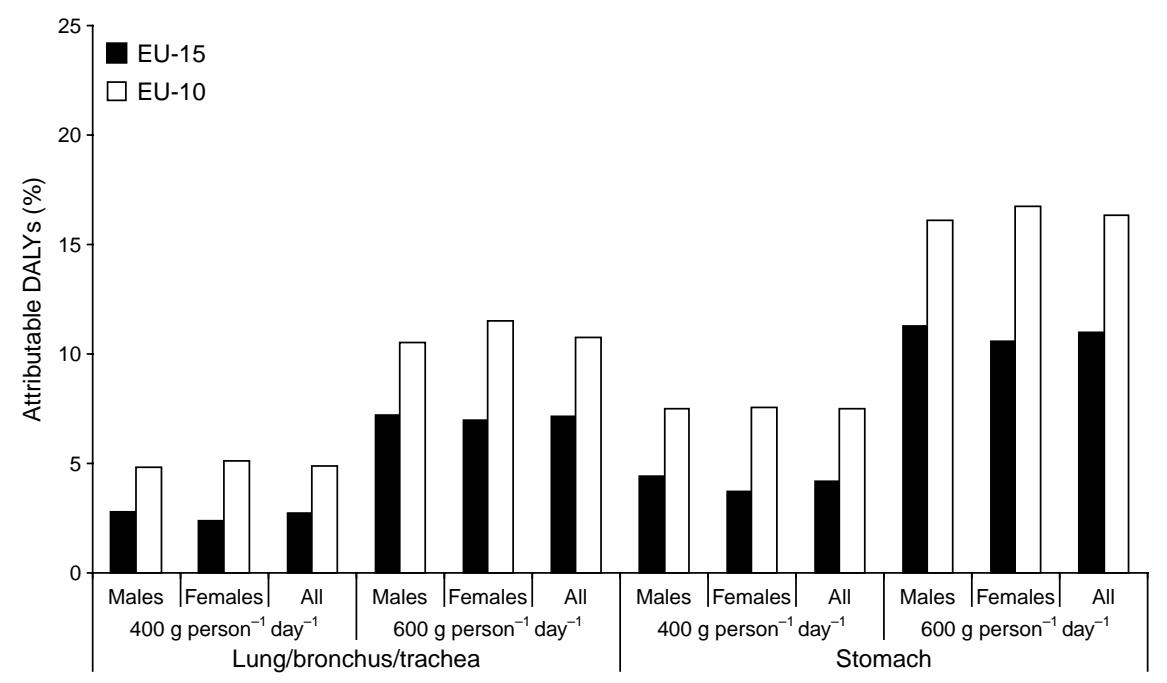

Fig. 2 Potential reduction in the burden of cancers of the lung/bronchus/trachea and stomach (expressed in attributable disabilityadjusted life years, DALYs) due to low fruit and vegetable intake in the EU-15 and EU-10 that could be achieved if fruit and vegetable intake increased to 400 and 600 g person $^{-1}$ day $^{-1}$, by gender (figures for the year 2000). EU-15 - the 15 countries that were members of the European Union (EU) before May 2004; EU-10 - the 10 countries that then joined it

a much younger age then those living in the other Member States (results not shown).

\section{Discussion}

This study highlights the potentially large impact that increasing fruit and vegetable intake could have in reducing the burden of disease in the EU, particularly in the 10 countries that joined the EU in May 2004. Each year, up to $3.6 \%$ of the global burden of disease and 46000 deaths could potentially be saved in the EU-10 if people across the region consumed at least the amounts of fruit and vegetables that are eaten by the highest consuming countries in the EU, for example Greece or Spain. In comparison, $1.7 \%$ of the global burden of diseases and 121000 deaths in the EU-15 could be prevented annually through increased fruit and vegetable intake. The potential relative health gain for the different health outcomes examined also tends to be higher in the EU-10 than in the EU-15, and it is greatest for cardiovascular diseases, a main cause of health divide in Europe ${ }^{27}$ : the burden of ischaemic heart disease and stroke could be reduced by up to $24 \%$ and $15 \%$, respectively, in the EU-10 if fruit and vegetable consumption increased to 600 g person $^{-1}$ day $^{-1}$, compared with $17 \%$ and $10 \%$, respectively, in the EU-15. 


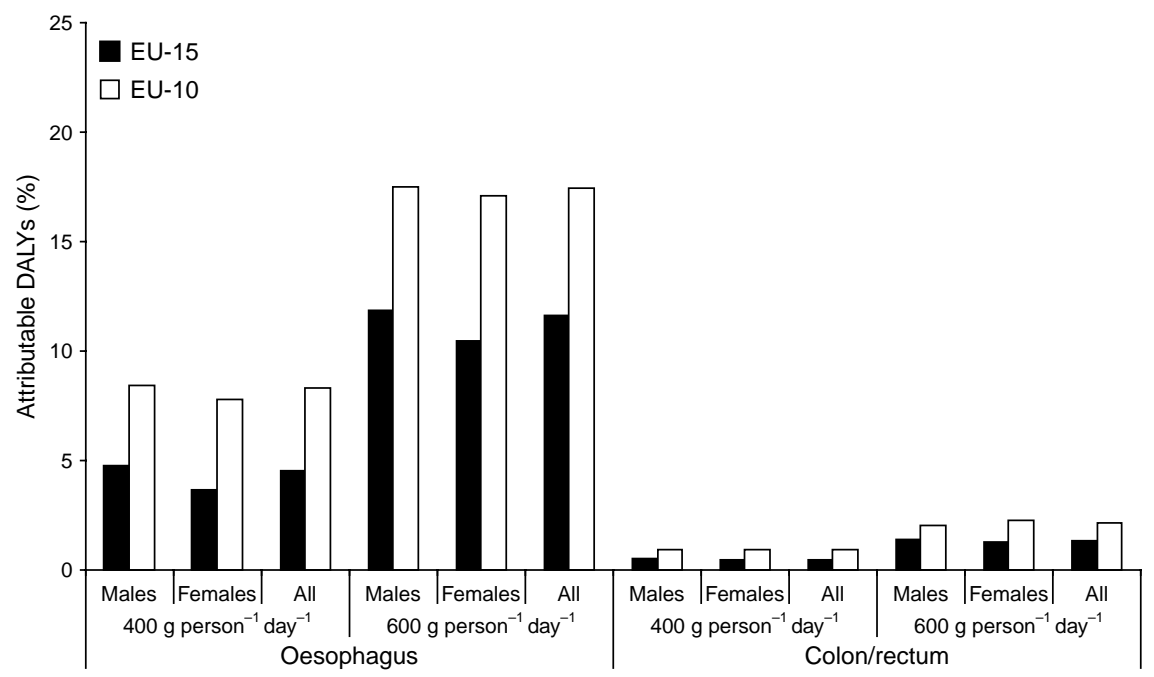

Fig. 3 Potential reduction in the burden of cancers of the oesophagus and colon/rectum (expressed in attributable disability-adjusted life years, DALYs) due to low fruit and vegetable intake in the EU-15 and EU-10 that could be achieved if fruit and vegetable intake increased to 400 and 600 g person $^{-1}$ day $^{-1}$, by gender (figures for the year 2000). EU-15 - the 15 countries that were members of the European Union (EU) before May 2004; EU-10 - the 10 countries that then joined it

Table 2 Number of lives that could be saved from ischaemic heart disease, ischaemic stroke and selected cancers in the European Union if fruit and vegetable consumption increased to 400 and 600 g person $^{-1}$ day $^{-1}$, by gender (figures for the year 2000)

\begin{tabular}{|c|c|c|c|c|c|c|}
\hline & \multicolumn{3}{|c|}{ EU-15 } & \multicolumn{3}{|c|}{ EU-10 } \\
\hline & Males & Females & All & Males & Females & All \\
\hline $\begin{array}{l}\text { Total population } \\
\text { Ischaemic heart disease }\end{array}$ & 185099920 & 193957820 & 379057740 & 35945990 & 38549213 & 74495203 \\
\hline 400 g person $^{-1}$ day $^{-1}$ & 17265 & 11942 & 29207 & 8204 & 5877 & 14081 \\
\hline 600 g person $^{-1}$ day $^{-1}$ & 45083 & 34181 & 79264 & 18368 & 13936 & 32303 \\
\hline \multicolumn{7}{|l|}{ Ischaemic stroke } \\
\hline 400 g person $^{-1}$ day $^{-1}$ & 3072 & 4109 & 7181 & 1249 & 1661 & 2911 \\
\hline 600 g person $^{-1}$ day $^{-1}$ & 8331 & 12040 & 20371 & 2989 & 4080 & 7068 \\
\hline \multicolumn{7}{|c|}{ Lung/bronchus/trachea cancer } \\
\hline 400 g person $^{-1}$ day $^{-1}$ & 3518 & 1048 & 4566 & 1357 & 418 & 1774 \\
\hline 600 g person $^{-1}$ day $^{-1}$ & 9392 & 3049 & 12441 & 3102 & 959 & 4061 \\
\hline \multicolumn{7}{|l|}{ Stomach cancer } \\
\hline 400 g person $^{-1}$ day $^{-1}$ & 1202 & 718 & 1920 & 490 & 322 & 812 \\
\hline 600 g person $^{-1}$ day $^{-1}$ & 3179 & 2068 & 5247 & 1116 & 737 & 1853 \\
\hline \multicolumn{7}{|l|}{ Oesophagus cancer } \\
\hline 400 g person $^{-1}$ day $^{-1}$ & 807 & 217 & 1024 & 211 & 38 & 250 \\
\hline 600 g person $^{-1}$ day $^{-1}$ & 2089 & 626 & 2715 & 458 & 88 & 546 \\
\hline \multicolumn{7}{|l|}{ Colon/rectum cancer } \\
\hline 400 g person $^{-1}$ day $^{-1}$ & 248 & 170 & 418 & 93 & 87 & 179 \\
\hline 600 g person $^{-1}$ day $^{-1}$ & 697 & 510 & 1207 & 224 & 205 & 430 \\
\hline \multicolumn{7}{|l|}{ All health outcomes } \\
\hline 400 g person $^{-1}$ day $^{-1}$ & 26112 & 18203 & 44315 & 11605 & 8403 & 20007 \\
\hline 600 g person $^{-1}$ day $^{-1}$ & 68772 & 52473 & 121245 & 26256 & 20005 & 46261 \\
\hline
\end{tabular}

EU-15 - the 15 countries that were members of the European Union (EU) before May 2004; EU-10 - the 10 countries that then joined it.

Food balance sheet statistics from the FAO and survey data suggest that most populations in the EU are not consuming adequate amounts of fruit and vegetables, especially in many new Member States $3,20,23,28$. However, even in southern and central Europe where climate and agricultural conditions are ideal to produce fruit and vegetables throughout the year ${ }^{29}$, few countries meet the recommended target population intake. We must also recognise that fruit and vegetable intake in a population is unlikely to be normally distributed; it tends to be skewed to the right, so that a large proportion of the population of each country will consume very little $\mathrm{e}^{30,31}$. The potential for public health actions to improve fruit and vegetable intake is thus considerable.

Although low fruit and vegetable intake is only one of the many contributory factors to cardiovascular disease and cancer, its importance is not negligible. For example, findings from the GBD study have shown that $28 \%$ of the burden of ischaemic heart disease in developed regions of the world (including Europe, North America, Australasia 
Table 3 Potential reduction in the burden of ischaemic heart disease, ischaemic stroke and selected cancers (expressed in disability-adjusted life years, DALYs) in the European Union that could be achieved if fruit and vegetable intake increased to 400 and $600 \mathrm{~g}$ person ${ }^{-1}$ day $^{-1}$, by gender (figures for the year 2000)

\begin{tabular}{|c|c|c|c|c|c|c|}
\hline & \multicolumn{3}{|c|}{ EU-15 } & \multicolumn{3}{|c|}{ EU-10 } \\
\hline & Males & Females & All & Males & Females & All \\
\hline $\begin{array}{l}\text { Total population } \\
\text { Ischaemic heart disease }\end{array}$ & 185099920 & 193957820 & 379057740 & 35945990 & 38549213 & 74495203 \\
\hline 400 g person $^{-1}$ day $^{-1}$ & 145781 & 58769 & 204550 & 88084 & 42158 & 130242 \\
\hline $\begin{array}{l}600 \text { g person }^{-1} \text { day }^{-1} \\
\text { Ischaemic stroke }\end{array}$ & & 276141 \\
\hline 400 g person $^{-1}$ day $^{-1}$ & 36236 & 29263 & 65500 & 17081 & 16310 & 33390 \\
\hline 600 g person $^{-1}$ day $^{-1}$ & 93043 & 83545 & 176588 & 37584 & 36961 & 74544 \\
\hline \multicolumn{7}{|c|}{ Lung/bronchus/trachea cancer } \\
\hline 400 g person $^{-1}$ day $^{-1}$ & 31669 & 9428 & 41097 & 14959 & 4593 & 19552 \\
\hline 600 g person $^{-1}$ day $^{-1}$ & 81813 & 27449 & 109262 & 32706 & 10330 & 43036 \\
\hline 400 g person $^{-1}$ day $^{-1}$ & 10604 & 5424 & 16028 & 5367 & 3171 & 8538 \\
\hline 600 g person $^{-1}$ day $^{-1}$ & 26978 & 15435 & 42413 & 11546 & 7012 & 18558 \\
\hline \multicolumn{7}{|l|}{ Oesophaqus cancer } \\
\hline 400 g person $^{-1}$ day $^{-1}$ & 8395 & 1611 & 10006 & 2671 & 383 & 3054 \\
\hline 600 g person $^{-1}$ day $^{-1}$ & 20962 & 4616 & 25577 & 5567 & 845 & 6412 \\
\hline \multicolumn{7}{|l|}{ Colon/rectum cancer } \\
\hline 400 g person $^{-1}$ day $^{-1}$ & 2547 & 1763 & 4309 & 1016 & 893 & 1908 \\
\hline 600 g person $^{-1}$ day $^{-1}$ & 6959 & 5347 & 12306 & 2356 & 2105 & 4460 \\
\hline \multicolumn{7}{|l|}{ All health outcomes } \\
\hline 400 g person $^{-1}$ day $^{-1}$ & 235232 & 106258 & 341490 & 129177 & 67508 & 196685 \\
\hline 600 g person $^{-1}$ day $^{-1}$ & 592039 & 300434 & 892473 & 273378 & 149774 & 423152 \\
\hline
\end{tabular}

EU-15 - the 15 countries that were members of the European Union (EU) before May 2004; EU-10 - the 10 countries that then joined it.

and Japan) could be attributed to a lack of fruit and vegetables in the diet. This compares with 58\% from high blood pressure, 63\% from high cholesterol, 33\% from overweight, $22 \%$ from physical inactivity, $22 \%$ from tobacco and $0.2 \%$ from alcohol intake - for a combined effect reaching 89 to $93 \%$ (the combined burden is typically less than the sum of individual risks) ${ }^{32}$. As, in addition, several major risk factors for important non-communicable diseases have significant dietary components (e.g. blood pressure, blood cholesterol, overweight), there is a need for a much greater emphasis on diet within European public health policy as a means of reducing the health divide within the Union. The Finnish experience has shown that significant major dietary change, including increased fruit and vegetable intake, is possible over a reasonable time $\operatorname{span}^{33}$.

During recent decades, the importance of public health nutrition has increasingly been recognised in Europe $e^{2,34}$. In the EU, there has been much support, both direct and indirect, for higher intakes ${ }^{35}$. This includes, among others, the European Commission-funded 'Eurodiet' project ${ }^{36}$, the Commission's White Paper on Food Safety in $2000^{37}$, the establishment of a European-wide food safety system in January $2002^{38}$, the adoption by the EU Council in December 2000 of a resolution on health and nutrition inviting actions to improve nutrition in the $\mathrm{EU}^{39}$, the adoption by the European Parliament and Council in 2002 of a new Community programme for public health for the years 2003-2008 (nutrition, physical activity and obesity are key priorities of this programme $)^{40}$, and in March 2005, the launch of the EU Platform for Action on Diet, Physical
Activity and Health ${ }^{41}$. WHO and FAO have also been playing a key role in the promotion of healthy nutrition in Europe. A major recent initiative, conducted by the WHO Regional Office for Europe, has been the development of a food and nutrition policy document and action plan for the European region for the years 2000-2005 $5^{42}$. This action plan, which stresses the need for concerted action by all sectors to develop and implement healthy food and nutrition policies (including increased fruit and vegetable intake), was endorsed by WHO European Member States in September 2000. Progress of nutrition policy in Europe and a draft of the 2nd Food and Nutrition Action Plan will be discussed at the 2006 WHO ministerial conference. In November 2003, WHO and FAO jointly launched a global initiative to promote the consumption of fruit and vegetables ${ }^{43,44}$ which fits within the framework of the WHO Global Strategy on Diet, Physical Activity and Health (endorsed in May 2004) and the implementation mandate of the WHO Global Strategy for the Prevention and Control of Non-communicable Disease. This effort has been developed in collaboration with other partners, including national '5-a-Day' type multi-stakeholder organisations which promote fruit and vegetable intake.

Clearly, the promotion of fruit and vegetable consumption in the EU requires an intersectoral approach targeting both the demand for and the supply of fruit and vegetables, and involving the many potential stakeholders in the public and private sectors, non-governmental organisations, civil society and international bodies ${ }^{45}$. It should also involve actions at both the EU and national level. Unfortunately, many governments continue to rely 
on health education as the main strategy to promote fruit and vegetable intake, appealing to individuals to take responsibility for their food choices. Yet, while nutritional education is an important pillar of improved dietary intake, it cannot be sufficient to tackle the growing burden of cardiovascular diseases and cancer in the EU. Moreover, the EU allocates only a small budget for health education and the promotion of fruit and vegetables. This is inadequate in comparison with the large global marketing budget for food promotion ${ }^{31}$.

There should also be greater emphasis on promoting a food policy that targets the determinants of fruit and vegetable consumption, increasing the supply of, and access to, fruit and vegetables. This should be supported by clear and consistent food labelling to help consumers make informed choices, responsible marketing practices, nutrition programmes that take account of cultural specificities, and major action on the EU Common Agricultural Policy (CAP) ${ }^{46}$. Despite the potential health gains from increasing fruit and vegetable consumption, the effect of the CAP has actually led to higher prices of fruit and vegetables and reduced availability for consumers, with the most negative impact on low-income groups who already have the lowest fruit and vegetable intakes and highest risks of non-communicable diseases ${ }^{29,46-48}$.

More research is needed, at several levels. First, additional investigations are needed to provide clearer explanations of the observed beneficial effects of fruit and vegetables in cardiovascular diseases and cancer prevention, particularly outside western Europe (where most European studies have taken place ${ }^{20}$ ); this should include the ascertainment of which food constituents provide benefits and the role of exposure to fruit and vegetable intake over the life course. Research should examine in more depth the effectiveness of interventions designed to increase consumption in different settings, including the economic evaluation of their effectiveness ${ }^{44}$. These initiatives should be informed by a standardised nutrition surveillance system that would allow for comparisons among countries and socio-economic subgroups over time $29,49,50$

The burden of disease estimates presented in this report are subject to the limitations imposed by the methods used, which have been designed to allow assessment of a wide range of diverse exposures ${ }^{25,32}$. Such quantitative risk assessment is inevitably subject to considerable uncertainty surrounding the estimation of exposure levels (here levels of fruit and vegetable intake) and exposureoutcome relationships (relative risks levels), the selection of the target of choice, and the statistical methods used to obtain disease burden estimates ${ }^{16,20}$. This uncertainty also includes the nature of the exposure-response relationship (e.g. whether there is a threshold effect for fruit and vegetables), the levels of bias in measurement, plus the extrapolation of exposure and relative risks from one population to another. None the less, the analyses presented here draw on the best evidence currently available and should be considered within the context of limited data as a first attempt to estimate the burden of disease attributable to low consumption of fruit and vegetables in the EU.

In conclusion, this study has shown that fruit and vegetables can play a potentially major role in reducing the burden of cardiovascular diseases and cancer in the EU. The impact could be particularly important in the 10 new Member States, where fruit and vegetable intake tends to be relatively low and mortality from cardiovascular disease particularly high compared with other Member States $2,3,19,20,51,52$. EU public health policy is increasingly recognising the importance of a healthy diet and is now leading to action. However, substantial political will, financial investment and coordinated efforts that take account of the economic, social and cultural specificities of each Member State, including variations in food insecurity ${ }^{53,54}$, are still needed to impact significantly on fruit and vegetable intake throughout the region. These efforts should yield a rich dividend in the long term and help reduce the health divide in the EU.

\section{Acknowledgements}

This project was supported by a grant from the English Department of Health and funding from the European Heart Network to estimate the burden of cardiovascular disease due to low fruit and vegetable intake in the European Union. However, the English Department of Health and the European Heart Network cannot accept responsibility for any information provided or views expressed. We would like to thank Colin Mathers (World Health Organization, Geneva) and Steve Van der Hoorn (University of Auckland, New Zealand) who provided death and disability estimates and calculation formulae. We also wish to thank the people who helped in providing sources of data on fruit and vegetable intake (these are listed in full elsewhere ${ }^{20}$ ).

\section{References}

1 World Health Organization (WHO). Diet, Nutrition and the Prevention of Chronic Diseases. Report of a Joint Food and Agriculture Organization/WHO Expert Consultation. WHO Technical Report Series No. 916. Geneva: WHO, 2003.

2 Williams C, McColl K, Cowburn G. Food, Nutrition and Cardiovascular Disease Prevention in the European Region: Challenges for the New Millennium. Brussels: European Heart Network, 2002.

3 Petersen S, Rayner M, Leal J, Luengo-Fernandez R, Gray A. European Cardiovascular Disease Statistics. 2005 ed. Oxford: British Heart Foundation, 2005.

4 Ness AR, Powles JW. Fruit and vegetables, and cardiovascular disease: a review. International Journal of Epidemiology 1997; 26: 1-13. 
5 Law M, Morris J. By how much does fruit and vegetable consumption reduce the risk of ischaemic heart disease? European Journal of Clinical Nutrition 1998; 52: 549-56.

6 World Cancer Research Fund (WCRF)/American Institute for Cancer Research (AICR). Food, Nutrition and the Prevention of Cancer: A Global Perspective. Washington, DC: AICR, 1997

7 International Agency for Research on Cancer (IARC). Handbooks of Cancer Prevention. Vol. 8. Fruit and Vegetables. Lyon: IARC Press, 2003.

8 Ribioli E, Norat T. Epidemiologic evidence of the protective effect of fruit and vegetables on cancer risk. American Journal of Clinical Nutrition 2003; 78(Suppl.): 559S-69S.

9 Klerk M, Jansen M, van't Veer P, Kok F. Fruits and Vegetables: Chronic Disease Prevention. Wageningen: Wageningen Agricultural University, 1998.

10 Bazzano LA. Dietary Intake of Fruits and Vegetables and Risk of Diabetes Mellitus and Cardiovascular Diseases. Geneva: World Health Organization, 2005.

11 Tobias M. The Burden of Disease and Injury in New Zealand. Wellington: Ministry of Health, 2001.

12 Mathers C, Vos T, Stevenson C. The Burden of Disease and Injury in Australia. Canberra: Australian Institute of Health and Welfare, 1999.

13 National Institute of Public Health. Determinants of the Burden of Disease in the EU. Stockholm: National Institute of Public Health, 1997.

14 Joffe M, Robertson A. The potential contribution of increased vegetable and fruit consumption to health gain in the European Union. Public Health Nutrition 2001; 4: 893-901.

15 World Health Organization (WHO). The World Health Report 2002: Reducing Risks, Promoting Healthy Life. Geneva: WHO, 2002.

16 Lock K, Pomerleau J, McKee M, Altmann DR. The global burden of disease due to low fruit and vegetable consumption: implications for the global strategy on diet. Bulletin of the World Health Organization 2005; 83: 100-8.

17 European Community and World Health Organization (WHO) Regional Office for Europe. Health Status Overview for Countries of Central and Eastern Europe that are Candidates for Accession to the European Union. Copenhagen: WHO Regional Office for Europe, 2002.

18 McKee M. The implications for health of European Union enlargement. British Medical Journal 2004; 328: 1025-6.

19 World Health Organization (WHO) Regional Office for Europe. European Health for All Database. January 2005 update. Copenhagen: WHO Regional Office for Europe, 2005.

20 Lock K, Pomerleau J, Causer L, McKee M. Low fruit and vegetable consumption. In: Ezzati M, Lopez AD, Rodgers A, Murray CJL, eds. Comparative Quantification of Health Risks. Global and Regional Burden of Disease Attributable to Selected Major Risk Factors. Vol. 1. Geneva: WHO, 2004; 597-728.

21 Pomerleau J, Lock K, McKee M, Altmann DR. The challenge of measuring global fruit and vegetable intake. Journal of Nutrition 2004; 134: 1175-80.

22 Kelly A, Becker W, Helsing E. Food balance sheets. In: Becker W, Helsing E, eds. Food and Health Data. Their Use in Nutrition Policy-making. World Health Organization (WHO) Regional Publications, European Series, No. 34. Copenhagen: WHO Regional Office for Europe 1991; 39-48.

23 Food and Agriculture Organization of the United Nations (FAO). FAOstat Statistical Database. Rome: FAO, 2005. Also available at http://faostat.fao.org/. Accessed 8 November 2005.

24 United Nations Population Division. World Population Prospects: The 2002 Revision. New York: United Nations, 2003
25 Murray C, Lopez AD. On the comparable quantification of health risks: lessons from the Global Burden of Disease Study. Epidemiology 1999; 10: 594-605.

26 Ezzati M, Lopez AD, Rodgers A, Murray CJL, eds. Comparative Quantification of Health Risks: The Global and Regional Burden of Disease Attributable to Selected Major Risk Factors. Geneva: World Health Organization, 2004.

27 Bobak M, Marmot M. East-West mortality divide and its potential explanations: proposed research agenda. British Medical Journal 1996; 312: 421-5.

28 Pomerleau J, McKee M, Kadziauskiene K, Abaravicius A, Vaask S, Pudule I, et al. Macronutrient and food intake in the Baltic Republics. European Journal of Clinical Nutrition 2001; 55: 200-7.

29 Robertson A, Tirado C, Lobstein T, Jermini M, Knai C, Jensen $\mathrm{JH}$, et al. Food and Health in Europe: A New Basis for Action. World Health Organization (WHO) Regional Publications, European Series, No. 96. Copenhagen: WHO Regional Office for Europe, 2004.

30 Trichopoulou A. Nutrition in Europe: Nutrition Policy and Public Health in the European Community and Models for European Eating Habits on the Threshold of the 21st Century. Brussels: European Parliament Scientific and Technological Options Assessment, 1997.

31 Lobstein T. Suppose we all ate a healthy diet. Eurobealth 2004; 10: 8-12

32 Ezzati M, Vander Hoorn S, Rodgers A, Lopez AD, Mathers CD, Murray CJL. Comparative Risk Assessment Collaborating Group. Estimates of global and regional potential health gains from reducing multiple major risk factors. Lancet 2003 ; 362: $271-80$

33 Vartiainen E, Jousilahti P, Alfthan G, Sundvall J, Pietinen P, Puska P. Cardiovascular risk factor changes in Finland, 1972-1997. International Journal of Epidemiology 2000; 29: 49-56.

34 Pomerleau J, McKee M, Lobstein T, Knai C. The burden of disease attributable to nutrition in Europe. Public Health Nutrition 2003; 6: 453-61.

35 Directorate-General for Health and Consumer Protection of the European Commission. Status Report on the European Commission's Work in the Field of Nutrition in Europe. Brussels: European Communities, 2002.

36 Eurodiet. Nutrition \& Diet for Healthy Lifestyles in Europe: Science \& Policy Implications [online], 2000. Available at http://europa.eu.int/comm/health/ph/programmes/health/ reports/report01_en.pdf. Accessed 8 November 2005.

37 Commission of the European Communities. White Paper on Food Safety. Brussels: Commission of the European Communities, 2000.

38 Food Law/European Food Safety Authority-European Food Safety Authority adopted-council agrees key legislation putting a new European-wide food safety system in place. Commission Press Release (IP/02/100), 21 January 2002. Available at http://www.foodlaw.rdg.ac.uk/news/en02003.htm. Accessed 19 May 2006.

39 European Communities Council. Council resolution of 14 December 2000 on health and nutrition. Official Journal of the European Communities C 20, 23.1.2001, 2001.

40 European Communities Council. Decision No. 1786/2002/EC of the European Parliament and of the Council of 23 September 2002 adopting a programme of Community action in the field of public health (2003-2008). Official Journal of the European Communities L271 09.10.2002, 2002. Also available at http://europa.eu.int/eurlex/pri/en/oj/dat/2002/1-271/1-27120021009en00010011.pdf. Accessed 19 May 2006

41 National Institute of Public Health and the Environment (RIVM). Baseline actions 2004/2005 (Second Update/29 March 2006 1200). EU Platform on Diet, Physical Activity and Health. Bilthoven: RIVM, 2006. Also available at 
http://ec.europa.eu/comm/health/ph_determinants/life_style/platform/docs/synopsis_baselines.pdf. Accessed 19 May 2006.

42 World Health Organization (WHO) Regional Office for Europe. The First Action Plan for Food and Nutrition Policy. WHO European Region 2000-2005. Copenhagen: WHO Regional Office for Europe, 2001

43 World Health Organization (WHO). Fruit and Vegetable Promotion Initiative. A Meeting Report, Geneva, 25-27 August 2003. Geneva: WHO, 2003.

44 Pomerleau J, Lock K, Knai C, McKee M. Effectiveness of Interventions and Programmes Promoting Fruit and Vegetable Intake. Background paper for the Joint Food and Agriculture Organization/WHO Workshop on Fruit and Vegetables for Health, Kobe, Japan, 1-3 September 2004. Geneva: WHO, 2005.

45 World Health Organization (WHO) and Food and Agriculture Organization of the United Nations (FAO). Fruit and Vegetables for Health. Report of a Joint FAO/WHO Workshop, Kobe, Japan, 1-3 September 2004. Geneva: WHO, 2005.

46 Lock K, Pomerleau J. Fruit and Vegetable Policy in the European Union: Its Effect on the Burden of Disease. Brussels: European Heart Network, 2005.

47 Dowler E. Inequalities in diet and physical activity in Europe. Public Health Nutrition 2001; 4: 701-9.
48 European Commission. The Health Status of the European Union. Narrowing the Health Gap. Luxembourg: Office for Official Publications of the European Communities, 2003.

49 Agudo A. Measuring Intake of Fruit and Vegetables. Background paper for the Joint Food and Agriculture Organization/WHO Workshop on Fruit and Vegetables for Health, Kobe, Japan, 1-3 September 2004. Geneva: WHO, 2005.

50 Roos G, Prättälä R. Disparities in Food Habits. Review of Research in 15 European Countries. Helsinki: National Public Health Institute, 1999.

51 Ginter E. High cardiovascular mortality in postcommunist countries: participation of oxidative stress? International Journal for Vitamin and Nutrition Research 1996; 66: 183-9.

52 Zatonski WA, McMichael AJ, Powles JW. Ecological study of reasons for sharp decline in mortality from ischaemic heart disease in Poland since 1991. British Medical Journal 1998; 316: $1047-51$.

53 Rokx C, Galloway R, Brown L. Prospects for Improving the Nutrition Situation in Eastern Europe and Central Asia. New York: World Bank, 2000.

54 Pomerleau J, McKee M, Robertson A, Vaask S, Pudule I, Grinberga D, et al. Food security in the Baltic Republics. Public Health Nutrition 2002; 5: 397-404. 